\title{
EDUKASI MANFAAT SAYUR DAN BUAH PADA REMAJA DENGAN STATUS OBESITAS DI SMA N 8 DASAN CERMEN KOTA MATARAM
}

\author{
Joyeti Darni ${ }^{1^{*}}$, Retno Wahyuningsih ${ }^{2}$ \\ 1-2Politeknik Kesehatan Kementerian Kesehatan Mataram \\ Email korespondensi: ummunailah21@gmail.com \\ Disubmit: 14 Juli 2021 \\ Diterima: 26 Juli 2022 \\ Diterbitkan: 02 Februari 2022 \\ DOI: https://doi.org/10.33024/jkpm.v5i2.4677
}

\begin{abstract}
ABSTRAK
Obesitas atau kelebihan berat badan sebagai akibat penimbunan lemak yang berlebihan pada remaja merupakan masalah yang serius karena akan berlanjut hingga usia dewasa dan pencetus terjadinya penyakit kronis dan degeneratif. Pola makan merupakan perilaku paling penting dalam mempengaruhi keadaan gizi seseorang. Sayuran dan buah-buahan merupakan sumber berbagai vitamin, mineral dan serat pangan. Orang Indonesia dianjurkan konsumsi sayuran dan buah-buahan 400-600 g per orang per hari bagi remaja dan orang dewasa, dengan dua pertiga dari jumlah anjuran tersebut adalah porsi sayur. Tujuan Pengabdian dilakukan untuk meningkatkan pemahaman dan kesadaran siswa tentang pentingnya konsumsi sayur dan buah sesuai dengan anjuran untuk remaja. Metode yang digunakan adalah penyuluhan dengan media Lcd, pemberian games tentang pentingnya sayur dan buah-buahan, serta pemberian makanan tambahan berupa buah-buahan. Evaluasi kegiatan menggunakan kuesioner tingkat pengetahuan pre-post test. Hasil rata-rata pengetahuan sebelum penyuluhan skor benar $<60$ sebanyak $12,5 \%$, setelah pemberian edukasi nilai responden $<60$ sudah tidak ada lagi. Skor pengetahuan sebelum penyuluhan yang mendapatkan nilai $>80$ sebanyak $0 \%$ dan nilai $>80$ mengalami peningkatan setelah penyuluhan sebanyak $45,8 \%$.
\end{abstract}

Kata Kunci: buah, obesitas, remaja, sayur

\begin{abstract}
Obesity or being overweight as a result of excessive fat accumulation in adolescents is a serious problem because it will continue into adulthood and lead to chronic and degenerative diseases. Diet is the most important behavior in influencing a person's nutritional status. Vegetables and fruits are a source of various vitamins, minerals and dietary fiber. It is recommended that Indonesians consume 400-600 g of vegetables and fruit per person per day for adolescents and adults, with two-thirds of the recommended portion being vegetables. The purpose of service was carried out to increase students' understanding and awareness of the importance of consuming vegetables and fruit in accordance with recommendations for adolescents. The method used is counseling with LCD media, giving games about the importance of vegetables and fruits, and providing additional food in the form of fruits. Evaluation of activities using a pre-post knowledge level questionnaire. The results of the average knowledge before counseling correct score $<60$ as much as 12,5\%, after giving counseling
\end{abstract}


the respondent's score $<60$ is no longer there. Knowlwdge score before counseling get a value of $>80$ as much as $0 \%$ and increased after counseling as much as $45,8 \%$.

Keywords: vegetables, fruit, adolescents, obesity

\section{PENDAHULUAN}

Obesitas pada remaja merupakan masalah yang serius karena akan berlanjut hingga usia dewasa dan pencetus terjadinya penyakit kronis dan degeneratif (Almatsier S, 2011). Menurut WHO bahwa 10 anak didunia telah mengalami kegemukan (Sartika DA, 2011). Kegemukan dan obesitas merupakan penimbunan lemak tubuh yang berlebih sehingga menyebabkan kelebihan berat badan (Kemenkes RI, 2012). Remaja yang mengalami obesitas atau kegemukan akan melakukan usaha dalam penurunan berat badan, caracara yang dilakukan remaja seringkali tidak tepat seperti melakukan pembatasan makanan atau berdiet ketat. Remaja seringkali memilih cara berdiet tanpa pengetahuan yang mencukupi, sehingga dapat mempengaruhi kondisi status gizinya, dilain sisi zat-zat gizi yang memadai masih sangat dibutuhkan pada remaja untuk pertumbuhan yang optimal. Sayur dan buahbuahan merupakan sumber berbagai vitamin, mineral dan serat pangan dapat membantu menurunkan berat badan karena bahan makanan ini mampu memberikan rasa kenyang lebih lama.

Pola makan merupakan perilaku paling penting dalam mempengaruhi keadaan gizi seseorang. Keadaan gizi yang baik dapat meningkatkan kesehatan individu dan masyarakat (Persagi dan Asdi, 2019). Sayuran dan buah-buahan merupakan sumber berbagai vitamin, mineral dan serat pangan. Orang Indonesia dianjurkan konsumsi sayuran dan buah-buahan 400-600 g per orang per hari bagi remaja dan orang dewasa, dengan dua pertiga dari jumlah anjuran tersebut adalah porsi sayur (Kemenkes Direktorat Jendral Bina Gizi dan Kesehatan Ibu dan Anak, 2014).

Kemenkes memperkenalkan Piring Makanku, yang selanjutnya disempurnakan menjadi Isi Piringku. Isi piringku dimaksudkan sebagai panduan yang menunjukkan proporsi makanan dari setiap kelompok makanan dalam satu piring. Visual Isi Piringku menganjurkan isilah separuh (50\%) dari piring dengan sayur dan buah dan separuh (Persagi dan ASDI, 2019). Kurang konsumsi sayur dan buah pada remaja obesitas dapat menyebabkan resiko terjadinya penyakit kronis dan degeneratif seperti hipertensi, hiperlipidemia dan DM tipe 2 (Persagi dan ASDI, 2019). Berdasarkan hasil penelitian pada remaja didapatkan bahwa pola makan merupakan faktor sisiko paling berpengaruh pada obesitas (Christine Hendra, 2016). Sebanyak $85.37 \%$ remaja menunjukkan kurangnya jumlah konsumsi sayur dan buah ( $\mathrm{Ni}$ Komang Desi Dina Purwita, 2018). Remaja dengan status gizi berat berlebih dan obesitas memiliki kemungkinan lebih besar yaitu 3,79 kali untuk memperoleh nilai akademis kurang dari rata-rata (Ayu Eka Cahyani, ID. 2015).

Hasil penelitian menyatakan bahwa asupan sayur dan buah-buahan yang rendah meningkatkan risiko kelebihan berat badan atau obesitas (Jihyun You and Jina Choo, 2016). Remaja memilih makanan tidak berdasarkan kandungan gizinya, tetapi lebih banyak dikarenakan untuk bersosialisasi dengan teman sebayanya atau untuk kesenangan semata (Khomsan, 2004). Data Riskesdas tahun 2018 menyebutkan $95.5 \%$ penduduk usia >10 tahun mengkonsumsi sayur dan buah kurang dari 5 porsi sehari (kemenkes, 2018). Padahal sayur dan buah- 
buahan di Indonesia banyak sekali macam dan jumlahnya. Sosialisasi untuk mengkonsumsi sayur dan buah-buahan sesuai anjuran harus dilakukan secara teratur, terutama untuk anak dan remaja agar dapat tercapai pertumbuhan yang optimal (Hariani, 2010). Pilihan farmakoterapi untuk pengobatan obesitas sangat terbatas, oleh karena itu program manejemen komprehensif yang menekankan pada asupan zat gizi yang tepat, aktivitas fisik dan modifikasi perilaku sangat penting sebagai advokasi pencegahan dan pengobatan obesitas sedini mungkin (Neslihan Koyuncuoglu gungor, 2014).

\section{MASALAH}

Kejadian kelebihan berat badan dan obesitas di SMA N 8 Kota Mataram termasuk banyak, jika dibandingkan data riset kesehatan dasar (Riskesdas) tahun 2018 menunjukkan angka 21,8\% untuk obesitas di Indonesia. Angka tersebut terus beranjak naik sejak tahun 2007 sebesar 10,5\% dan tahun 2013 sebesar $14,8 \%$. Modernitas membuat remaja terutama remaja perkotaan dimanjakan dengan semua teknologi dan fasilitas, pada akhirnya membuat sesorang minim bergerak. Pola makan remaja seringkali tidak beraturan, SMA N 8 yang berada di perkotaan memudahkan akses siswa untuk membeli makanan fast food/siap saji seperti fried chicken, french fries, pizza, burger, hot dog, ice cream dan sebagainya, namun tidak dibarengi dengan kebiasaan mengkonsumsi sayur dan buah-buahan sesuai dengan anjuran pedoman makan isi piringku. Sosialisasi berupa penyuluhan tentang pentingnya konsumsi sayur dan buah-buahan sangat penting dilakukan sebagai advokasi pencegahan dan pengobatan obesitas sedini mungkin.

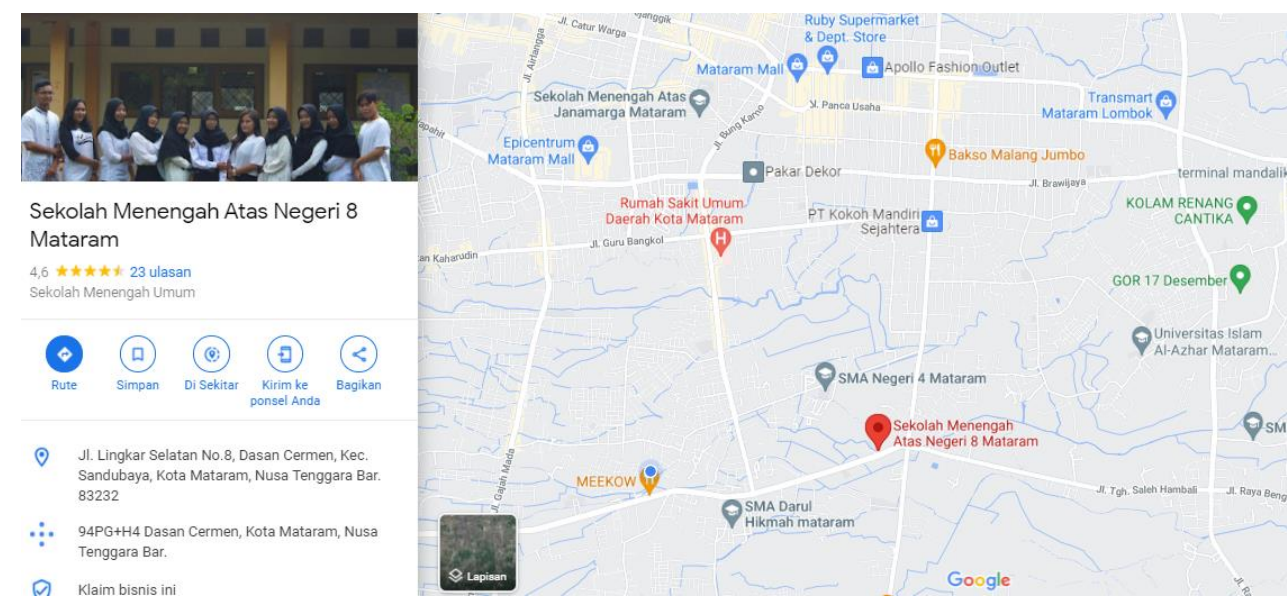

Gambar 1. Peta Lokasi Kegiatan PkM

\section{METODE}

\section{a. Tahap persiapan}

Sasaran kegiatan pengabdian kepada masyarakat ini adalah siswa dengan status gizi gemuk dan obesitas. Pengabdian di SMA N 8 Kelurahan Dasan Cermen Kota Mataram Provinsi NTB. Tahap persiapan dari kegiatan diawali dengan survey lokasi, mengurus surat-surat ijin lokasi yang akan digunakan sebagai tempat pengabdian masyarakat. Persiapan alat-alat yang digunakan dalam kegiatan pengabdian ini berupa alat antropometri terdiri dari timbangan injak untuk mengukur berat badan dan microtoise 
untuk mengukur tinggi badan. Persiapan formulir yang digunakan adalah kuesioner pre dan post tingkat pengetahuan sebelum dan sesudah pemberian edukasi tentang sayur dan buah, foto copyan handout materi dan daftar hadir. Persiapan alat penyuluhan yang digunakan adalah Lcd dan pengeras suara dan persiapan buah-buahan yang akan dibagikan pada saat kegiatan.

\section{b. Tahap pelaksanaan}

Metode edukasi yang digunakan adalah penyuluhan pada kelompok sasaran dengan menggunakan alat bantu media Lcd, games tentang pentingnya sayur dan buah-buahan serta pemberian makanan tambahan yang terdiri dari buah-buahan. Sebelum siswa masuk ke dalam kelas, siswa akan diukur antropometri terdiri dari berat badan menggunakan timbangan injak dan microtoise untuk mengukur tinggi badan, mengisi daftar kehadiran, dan data tanggal lahir. Guru membantu untuk mentertibkan siswa agar dapat fokus pada saat kegiatan penyuluhan disampaikan. Sebelum penyuluhan dilaksanakan, siswa diberikan kuesioner tingkat pengetahuan. Media penyuluhan menggunakan $L C D$ dan pengeras suara.

Kegiatan pengabdian ini melibatkan Dosen sebagai narasumber, instruktur dan mahasiswa dibagian pengukuran antropometri, membagikan kuesioner pre dan post test, serta membagikan makanan tambahan berupa buah-buahan. Setelah melakukan penyuluhan dan sesi tanya jawab tentang manfaat sayur dan buah-buahan, dilanjutkan dengan melakukan games tentang sayur dan buah-buahan. Kegiatan selanjutnya yaitu pemberian makanan tambahan berupa buah-buahan kepada siswa. Kegiatan berakhir dengan memberikan kembali kuesioner post-test setelah semua rangkaian kegiatan.

\section{c. Evaluasi}

Sesi evaluasi dengan memberikan umpan balik berupa pertanyaan kepada responden, dengan membagikan kembali kuesioner post test dengan pertanyaan yang sama dengan isi pertanyaan pada pre test. Adapun penilaian untuk data pengetahuan yaitu ada 10 pertanyaan yang diberi nilai 1 untuk jawaban benar dan 0 untuk jawaban salah, kemudian skor jawaban benar di total dan dibagi dengan jumlah pertanyaan dan dikali 100 persen untuk mendapatkan skor akhir. Skor akhir tersebut kemudian dikategorikan menjadi : kategori baik jika $>80 \%$ nilai jawaban benar, kategori sedang 60 $80 \%$, dan kategori kurang bila $<60 \%$ jawaban benar.

\section{HASIL DAN PEMBAHASAN}

Kegiatan pengabdian kepada masyarakat ini telah di laksanakan sesuai rencana di SMA N 8 Kelurahan Dasan Cermen Kota Mataram Provinsi NTB pada tanggal 2 November 2019. Kegiatan pengukuran antropometri, kegiatan penyuluhan dan tanya jawab, kegiatan games sayur dan buah, serta pemberian makanan tambahan berupa buah-buahan telah dilaksanakan dengan lancar dan berjalan sangat baik. Antusias siswa tampak dari semangatnya siswa dalam berinteraksi saat kegiatan dilaksanakan. Berikut gambar kegiatan dari pengukuran antropometri TB dan BB, pelaksanaan penyuluhan, kegiatan games sayur dan buah, serta pemberian makananan tambahan berupa buah-buahan ke siswa. 


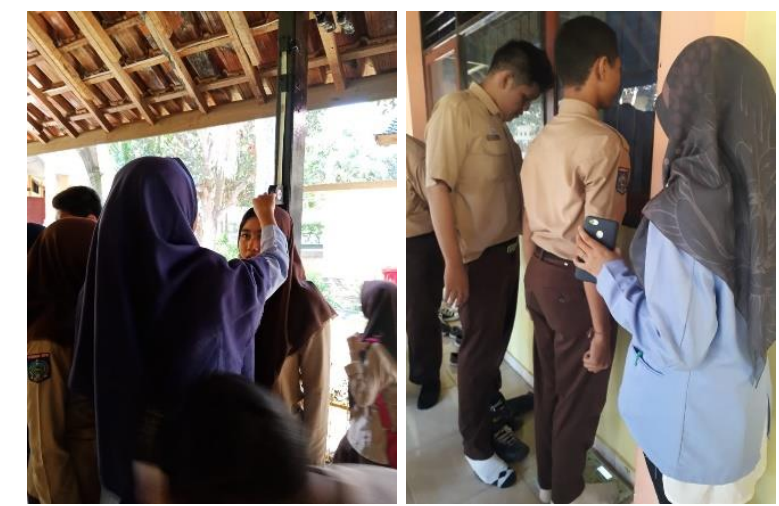

Gambar 2. Pengukuran antropometri TB dan BB
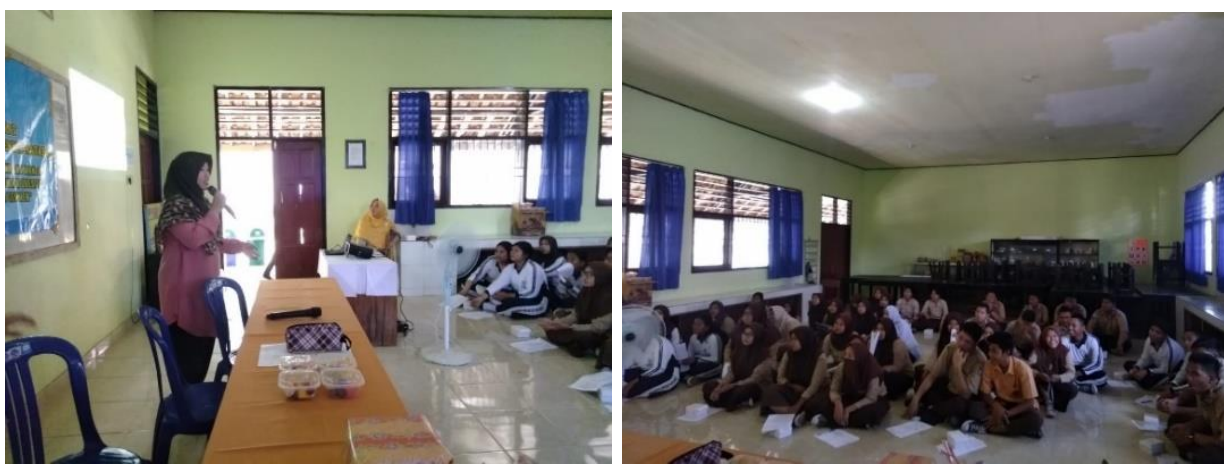

Gambar 3. Kegiatan penyuluhan dan tanya jawab
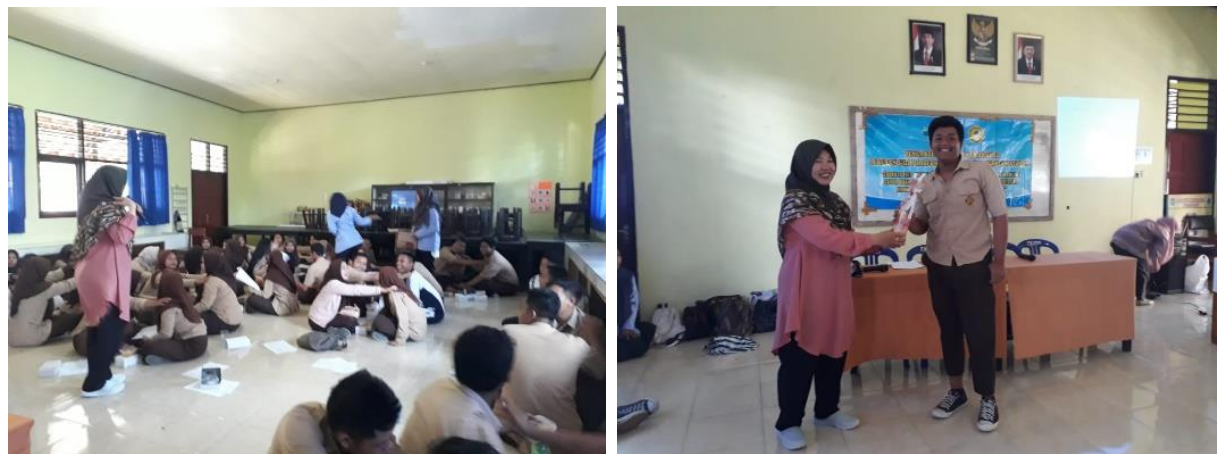

Gambar 4. Games tentang sayur dan buah serta pembagian hadiah

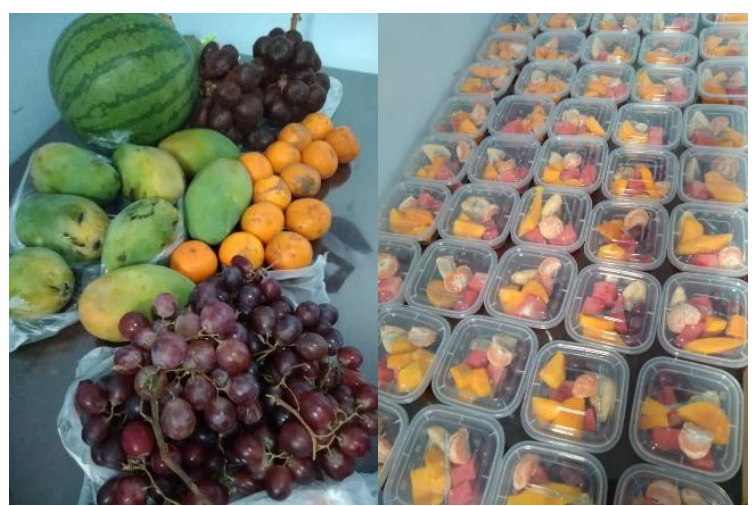

Gambar 5. Pemberian makanan tambahan buah-buahan 
Hasil pengabdian diketahui karakteristik siswa yang mengikuti kegiatan edukasi tidak hanya terdiri dari siswa dengan status kegemukan atau obesitas tetapi juga siswa dengan status gizi normal dikarenakan adanya permintaan dari pihak sekolah agar pemberian edukasi dapat diberikan kepada seluruh siswa dikelas. Adapun karakteristik peserta penyuluhan disajikan pada tabel 1

Tabel 1. karakteristik peserta penyuluhan

\begin{tabular}{lcc}
\hline \multicolumn{1}{c}{ Karakteristik } & $\mathrm{N}$ & $\%$ \\
\hline Umur (tahun) & 16 & 33,3 \\
15 & 15 & 31,3 \\
16 & 12 & 25 \\
17 & 4 & 8,3 \\
18 & 1 & 2,1 \\
20 & 48 & 100 \\
Jumlah & & \\
\hline Jenis Kelamin & 16 & 33,3 \\
Laki-laki & 31 & 62,75 \\
Perempuan & 48 & 100 \\
Jumlah & & \\
Status Gizi & 23 & 47,9 \\
Normal & 11 & 22,9 \\
Gemuk & 14 & 29,2 \\
Sangat Gemuk & 48 & 100 \\
Jumlah & &
\end{tabular}

Usia siswa yang mengikuti penyuluhan paling muda adalah usia 15 tahun sebanyak 33,3\% sedangkan jenis kelamin sebagian besar adalah jenis kelamin perempuan yaitu $66,7 \%$. Status gizi gemuk sebanyak $22,9 \%$ dan sangat gemuk sebanyak 29,2\%. Adapun hasil evaluasi tingkat pengetahuan pre-post test disajikan pada tabel 2 sebagai berikut:

Tabel 2. Hasil evaluasi

\begin{tabular}{ccccc}
\hline Kategori & \multicolumn{2}{c}{ Pre test } & \multicolumn{2}{c}{ Post test } \\
\cline { 2 - 5 } & $\mathrm{n}$ & $\%$ & $\mathrm{n}$ & $\%$ \\
\hline Baik $(>80)$ & 0 & 0 & 22 & 45,8 \\
Sedang $(60-80)$ & 42 & 87,5 & 26 & 54,2 \\
Kurang $(<60)$ & 6 & 12,5 & 0 & 0 \\
\hline
\end{tabular}

Hasil evaluasi menunjukan bahwa rata-rata pengetahuan sebelum penyuluhan dengan skor benar $<60$ sebanyak $12,5 \%$, setelah pemberian edukasi, tingkat pengetahuan mulai membaik dibuktikan dengan nilai responden yang $<60$ sudah tidak ada lagi. Skor pengetahuan sebelum penyuluhan dengan nilai benar 60-80 sebanyak $87,5 \%$ dan mengalami skor pengetahuan setelah penyuluhan mengalami penurunan sebanyak $54,2 \%$. Sedangkan sebelum penyuluhan yang mendapatkan nilai $>80$ sebanyak $0 \%$ dan mengalami peningkatan setelah penyuluhan sebanyak $45,8 \%$.

Pola makan pada remaja lebih menyukai makanan cepat saji atau fast food seperti fried chicken, pizza, burger, hot dog, ice cream dan lainnya dipromosikan secara gencar melalui media online sehingga remaja menjadi tertarik dan berdampak kepada perubahan pola makan lokal (Wulansari, 
2008). Penyuluhan yang diberikan merupakan pendidikan dengan mensosialisasikan pesan, menanamkan keyakinan, sehingga remaja tidak hanya sadar, tahu dan mengerti, namun juga bisa diterapkan dalam keseharian (Machfoed, 2010).

Peserta yang mengikuti pengabdian ini adalah siswa dengan usia sekolah yang mana rasa keingintahuannya cukup tinggi. Penyuluhan yang dilakukan dengan metode dua arah merupakan hal penting dalam pemberian edukasi, hal ini sejalan dengan penelitian Hamida (2012) bahwa media yang digunakan dalam proses pembelajaran akan menyebabkan proses penyuluhan menjadi lebih menarik.

\section{KESIMPULAN}

Pengabdian kepada masyarakat diikuti oleh 48 siswa. Pelaksanaan penyuluhan berjalan lancar dan hasil evalusi terdapat peningkatan pengetahuan sesudah diberikan edukasi tentang tentang manfaat sayur dan buah-buahan.

Adapun saran untuk kedepannya, diharapkan adanya kegiatan lanjutan secara berkala untuk memonitoring status gizi siswa dan pihak sekolah dapat memberikan himbauan promosi kesehatan dengan membawa bekal sehat sesuai pedoman isi piringku.

\section{DAFTAR PUSTAKA}

Almatsier S, Soetardjo S, Soekatri M. (2011). Gizi seimbang dalam daur kehidupan. Jakarta: Gramedia Pustaka.

Christine Hendra, Aaltje E. Manampiring, Fona budiarso. (2016). Faktor-faktor risiko terhadap obesitas pada remaja di kota Bitung. Jurnal e-Biomedik, Vol 4, No 1.

Hariani, dede. (2010). Pengaruh konsumsi buah dan sayur terhadap pengetahuan da sikap SD N 064975 Kota Medan. Sumatera Utara: Universitas Sumatera Utara

ID Ayu Eka Cahyani, IGL Sidiartha. (2015). Prevalensi berat badan berlebih dan obesitas dan hubungannya dengan nilai akademis pada remaja kelas sepuluh SMA N 1 Bangli. E-Jurnal Medika Udayana Vol 4 No 1.

Jihyun You dan Jina Choo. (2016). Adolescent Overweight and Obesity: Links to Socioeconomic Status and Fruit and Vegetable Intakes. Int. J. Environ. Res. Public Health 2016, 13, 307.

Kementerian Kesehatan Direktorat Jendral Bina Gizi dan Kesehatan Ibu dan Anak. (2014). Pedoman Gizi Seimbang. Jakarta: Kemenkes RI.

Kementerian Kesehahatan RI. (2012). Pedoman pencegahan dan penanggulangan kegemukan dan obesitas pada anak sekolah. Jakarta: Kemenkes RI.

Kementerian Kesehatan RI. (2018). Riset Kesehatan Dasar (Riskesdas) tahun 2018. Jakarta: Badan Penelitian dan Pengembangan Kementerian Kesehatan RI.

Khomsan. (2004). Pangan dan Gizi untuk Kesehatan. Jakarta: PT Rajagrafindo Persada

Machfoedz, Ircham dan Eko Suryani. (2010). Pendidikan kesehatan bagian dari promosi kesehatan. Yogyakarta: Fitramaya.

Neslihan Koyuncuoglu gungor. (2014). Overweight and Obesity in Children and Adolescents. J Clin Res Pediatr Endocrinol 2014;6(3):129-143 
Ni Komang Desi Dina Purwitas, I Ketut Kencana, AA Ngurah Kusumajaya. (2018). Gambaran Konsumsi Sayur dan Buah dengan Status Gizi Remaja di SMP N 3 Abiansemal Kabupaten Bdung. Jurnal Ilmu Gizi: Journal of Nutrition Science, Vol.7 No.3 (57-63).

Persatuan Ahli Gizi Indonesia dan ASDI. (2019). Penuntun Diet dan Terapi Gizi. Edisi ke-4. Jakarta: Buku Kedokteran EGC

Sartika DA. (2011). Faktor risiko obesitas pada anak 5-15 tahun di Indonesia. Jurnal Kesahatan Vol. 15. Jakarta: Universitas Indonesia

Wirakusumah ES. (2005). Buah dan sayur untuk terapi. Depok: Penebar Swadaya

Wulansari. (2008). Bahaya makanan cepat saji dan gaya hidup. Yogyakarta: 02 